\title{
Standards for university libraries: Evaluation of performance (draft)
}

\author{
Prepared by the ULS University Library Standards Review Committee \\ Kent H. Hendrickson, Chair
}

\section{Hearings on this draft will be held on July 10, 1988, at ALA Annual Conference in New Orleans.}

$\mathbf{T}$ proposed draft standard was prepared by an Ad Hoc University Library Standards Review Committee appointed prior to the ALA Midwinter Meeting in 1986. The committee members are $\mathrm{Pa}$ tricia L. Bril, California State University, Fullerton; Murray S. Martin, Tufts University; Richard W. Meyer, Clemson University; Maxine Reneker, Arizona State University; Jack A. Siggins, Yale University; and Kent Hendrickson, University of Nebraska-Lincoln (chair).

\section{Foreword}

The 1979 Standards were the product of a joint effort by ACRL and ARL and the cumulation of eleven years of work by several committees of both organizations. An excellent background on the development of standards for university libraries may be found in Beverly Lynch, "University Library Standards," Library Trends 31 (Summer 1982):33-47. Other articles and related documents will be referenced in appendices to accompany the final version of the standards in a future issue of C\&RL News.

As part of its charge, the Committee examined the existing Standards to decide whether a revision was needed. To assist in this effort and the actual revision the Committee solicited advice from other members of the university library community. First, open hearings were held during the ALA Midwinter Meeting in 1986; and second, a number of guests consulted with the Committee at ALA Annual Conference in 1986 and the 1987 Midwinter Meeting. Comments were also received from representatives of regional accrediting associations and selected university administrators.

Obviously the existence of this document indicates that the Committee determined that a revision was necessary. Many of the same issues discussed by the earlier committees were raised again. By far the most important of these was the question of whether standards should be quantitative or qualitative. In the end, based on the information received, we concluded that neither approach was appropriate. A model procedure for determining measurable expectations is the primary need.

This approach was chosen very carefully. In the course of its deliberations the Committee looked at three issues: Who uses standards? Why do they use them? What do they need? Standards are addressed to library managers, institutional managers, and evaluating bodies such as accreditation teams. While each of these groups may use standards to arrive at an evaluation of a library, they may do so for quite different reasons. Common needs, however, relate to how well the library is doing, how well it is supported, and how well it compares to other libraries. To answer these ques- 
tions facts are needed; not the kind that can be set out readily in a series of prescriptive statements or normative figures, but those gathered through the process described by these standards.

Basic to this document is the proposition that each university library system is unique and therefore should determine its own criteria for performance and evaluation. This process should be undertaken within the framework of the university's mission and goals. Another assumption is that, however the library is placed within the governing structure of the university, its relationship should be such that adequate communication flows to it concerning basic shifts in the mission of the university and changes in its programs. This document also assumes that the critical assessment resulting from the defined process will be transmitted appropriately throughout the university.

It is further assumed that within the library, administrators will have achieved the balance of hierarchical and collegial management which will allow the libraries' goals to be achieved, as well as adequate representation of staff views into the goal-setting and evaluation process, and appropriate development of the staff in the managerial, scholarly, and professional facets of their job responsibilities.

Finally, this document is necessarily prescriptive in several of its concepts. University libraries must become skilled in the process of examining and redefining as necessary their missions, establishing coherent goals whose attainment may be measured, continually and effectively assessing the needs of users, and identifying and applying those measures that will reveal the extent to which it has been successful in fulfilling its mission.

\section{Introduction}

These standards are intended to help members of the library and university administration responsible for determining priorities and evaluating performance to optimize the performance of the library in terms of the mission of the university.

While standards are needed, they cannot be stated as absolutes equally applicable to all universities and be useful. These standards are not a series of expectations or prescriptive sets of figures. They set forth the process by which expectations may be established, and enumerate the topics that should be addressed in the evaluation of university library performance.

These standards begin with a basic statement of purpose, explain the underlying assumptions and lead to a statement of expectations.

\section{Standards}

\section{General Statement of Purpose}

These standards set out the role of the university library within the context of the institution's infor- mation policies and academic goals. The mission of the university library is to provide information services in support of the teaching, research, and public service missions of the university. The achievement of that mission requires the development of standards to address the ways in which goals should be developed and measured, needed resources estimated, and success in goal achievement evaluated.

\section{UnDERLyING AsSUMPTIONS}

\section{(1) Centrality of the Library}

The library is of central importance to the institution. It is an organic combination of people, collections, and buildings, whose purpose is to assist users in the process of transforming information into knowledge.

Information and knowledge are central to the attainment of any university's goals. The ways in which information is collected, stored, and distributed within the institution will, in large measure, determine the level and success of scholarship and research. The institution needs clear policies concerning access to and provision of information. The library must take an active role in the development of these policies.

\section{(2) The Significance of the Investment in the Li- brary}

The library represents one of the largest cumulative capital investments on any campus. Libraries provide added value as part of all earning and research processes. The concept of the library as an investment is basic to these standards.

\section{(3) The Individual Nature of Each Library}

Each institution has a unique mix of goals, programs, and expectations influenced by its history and its current mission. As a result, the library serving the institution is unique. The application of prescriptive measures to a group of unique institutions has been rejected as inapposite. It is the use and interpretation of measures that is important in developing a process for managing change. The need is for a mixture of input and output measures, both qualitative and quantitative, but fundamentally process-oriented.

\section{(4) Technological Change}

The pace of technological change has rendered outmoded any concept of isolation and selfsufficiency. The library now exists within a complex information world, most of whose participants are not on campus. The library must be dynamic and future-oriented. This orientation does not seek change for its own sake, but recognizes the mutable nature of information in the computer age. Libraries will not abandon their traditional roles as collectors and conservators. Rather they will add new ones as facilitators and processors, and these new roles need to be recognized in the evaluation process. 


\section{Section A: Setting Goals and Objectives}

To determine the appropriate goals for a university library, representative bodies should engage in a continuing dialogue, carried out at several levels, and documented in a memorandum of understanding or a mission statement adopted by the governing board of the institution.

\section{(1) Participants}

The participants in the process of setting goals should include appropriate representatives from the following groups:

(a) University and library administration.

(b) Faculty.

(c) Library staff.

(d) Students.

(e) Trustees or regents.

(f) Advisory boards.

(g) State or other governmental units associated with the institution.

The roles of these constituencies vary, but their basic purpose is to bring to the discussions information concerning needs, goals, abilities, and points of view, as these affect the library.

\section{(2) Process}

The process is one of communication, both formal and informal, designed to increase the level of shared understanding concerning the goals and capabilities of the library.

Formal communication includes committee reports, the annual and special reports of the library and the institution, and discussion in the appropriate public forums.

The administrative organization of the university is in itself a means of communication and it is essential that the library, through its administration, be so placed as to have necessary access to the appropriate officers of the institution.

Informal communication is the result of daily contact between members of the community. The library staff should be able to participate fully in such contact. Continuous communication through the daily activities of the library also conveys a message about its role within the institution.

\section{(3) Product}

The object of this dialogue is to establish goals, provide for their measurement, and assess the degree to which they are reached.

The result should be a shared statement that may take various forms and cover various periods as determined by the institutional policies regarding such matters. The library is responsible for developing short- and long-term goals and objectives in response to this statement, again in consultation with the other participants in the dialogue.

A process of review and revision is required to keep current with need and capacity.

\section{Section B: Factors to be Considered in Developing Goals}

The development of goals and objectives requires that the resources needed and available to meet those goals be kept in mind. This section sets forth some of those factors.

The library consists of a combination of three resources: people; collections; and buildings. These resources are paid for from a budget. They need to be in correct proportion to one another to meet the service goals of the library. There are no comprehensive formulas for arriving at these proportions, but there are ways of determining whether the allocation of resources is in line with expectations.

\section{(1) Budgetary Support and Sources}

The library represents a major capital investment. As such, it requires ongoing annual investment to retain its value.

The sources of funding vary greatly, in accordance with the style of the parent institution. Whatever the source, the library should control its funds. Although there are many different methods of organizing and controlling budgets, the method chosen should make it possible for the library to operate without undue constraint.

(a) Capital Expenditures. It is customary to distinguish and separate major capital expenditures, such as new buildings, renovations, or automation from annual operating budgets. Added resources and services needed to keep up-to-date and maintain expanded plant are also needed.

Minor capital investments will be made each year for extensions or renovations. Adequate provision should be made for both kinds of capital expenditure.

(b) Operating Budget. The operating budget of the library must be appropriate to the mission of the library within the university. The budget should be developed interactively by the university and the library in accordance with the general practice of the institution. If it is impossible to meet all expectations or fund specific new programs, this should be made clear.

(c) Budgetary Control. The library must be responsible for the internal allocation and control of the approved budget, with provision for appropriate consultation. Transactions should be carried out in accordance with the accounting practices of the university. Those practices should recognize the special needs of the library, particularly in the acquisition of library materials.

(d) Maintenance. The complex modern library requires constant attention to ensure that it continues to function smoothly.

i. The library is responsible for the ongoing maintenance of its resources and services. This includes not only provision for replacement of equipment and library materials, but also keeping adequate statistics and other measures to determine 
whether the standards of service are being maintained.

ii. Appropriate budgetary provision should be made for replacement, repair, renovation, and investment in new and improved means of information access and delivery.

\section{(2) Human Resources}

The library is dependent on human resources skilled in the knowledge-based disciplines to achieve its goals. People select, acquire, process, and arrange the library's collections; they provide access to the information contained in those collections and the collections of other libraries; they direct its activities and provide its services.

(a) Level of Staffing. The library should be staffed in such a way as to meet the university's expectations. The numbers required are determined by the programs offered, the number of buildings, and the hours during which service is offered. While there are no absolute requirements, it is clear that the level of service is determined by the availability of staff.

(b) Kinds of Staff Needed. The staff should include librarians and other professionals, support staff, clerks, and students to provide services at the appropriate levels. The proportions of each group to the whole are determined by the programs supported and the locations served. The staff should incorporate the needed skills and academic training to meet the academic needs of the university, and to provide management support.

(c) Relationship to Other Staff. The director is responsible for all staff within the library and should ensure that the library adheres to the personnel policies and practices of the university. These policies and practices should recognize the special needs of librarians as working in the field of information.

To reflect the library's involvement in the academic programs of the university, librarians should have appropriate educational background, with training in library and information science as well as in other disciplines. Librarians require the protection necessary to ensure intellectual freedom, so that they may not be subject to improper pressure in matters of censorship, copyright, or selection of materials. They have the right, as professionals, to speak out on behalf of their professional concerns without fear of reprisal or dismissal.

(d) Organization. While there is no single best way of organizing a library, the investment in library staff is an investment in people rather than in positions. The organization should reflect this concept. There is general agreement that librarians should be able to exercise independent professional judgment within the rules, policies, and codes governing professional conduct; to participate in research and the work of professional organizations; to undertake consulting and other professional tasks; and to find advancement within the library without necessarily having to undertake adminis- trative and supervisory duties. Librarians should participate in the formulation of policies, in accordance with the style of the institution.

(e) Management. The library, under the director, should be responsible for managing its own affairs.

This autonomy does not abrogate the responsibility of the library for maintaining relationships with administration and faculty to achieve the dialogue recommended in these standards. The library should also adhere to local procedures and practices as they are stated by the appropriate university agencies.

(f) Staff Development. Librarians need to keep pace with the fields of library and information science, and other disciplines. The staff and the library administration have a joint responsibility for the development of skills. The administration should provide the leadership, resources, and management to foster the cooperative process, the goal being to ensure that the library retain the needed skills to provide proper service to the university.

\section{(3) Collections}

The primary goal of the library is to select, collect, organize, and provide access to all varieties of information for users. Library programs should be developed with that goal in mind.

(a) Collection Management. The library shall select and acquire materials in all formats to the level required to support academic programs.

i. Collection management includes not only purchase for retention, but also leasing, renting, deselection, providing access to other collections, including, as appropriate, planned resource-sharing and cooperative storage, and electronic access to databases.

ii. The collections should be extensive enough to support the academic programs offered, recognizing that there are instances where reliance can and should be placed on access to other resources rather than on ownership.

iii. There should be provision for adequate funding to ensure the addition of needed new resources, to maintain growth not only in existing areas of study and research, but also in newly added disciplines or extensions of existing disciplines.

iv. Recognition should be given to changes in the academic program. Equally, recognition should be given to library contributions to consortial or other resource-sharing programs.

$\mathrm{v}$. The collection management program of the library should be developed jointly by the library and the university, indicating the depth and breadth of the collections, as set out in an appropriate taxonomy. The policies setting out this program should be in written form, easily accessible, and regularly reviewed.

vi. The library is responsible for relations with vendors, contractors, and other agencies, and for reviewing the efficacy of such relationships.

(b) Collection Preservation. The library should 
have a program for the conservation and preservation of materials, either locally or with other libraries and agencies. Such a program should be integrated with national programs for conservation and preservation.

i. The library requires variable combinations of temperature and humidity control, and a program for fire and damage prevention. These should be provided and reassessed at regular intervals.

ii. The library should have an emergency plan to cover minor and major disasters and include both damage prevention and damage recovery. It should also provide for alternative service and management, and be co-ordinated with campuswide plans.

iii. The library should not only be able to provide for the care and preservation of its own collections, but able to participate in local, regional, and national preservation plans.

iv. The library should have adequate safeguards against loss, mutilation and theft. Since the library has a primary goal of maintaining open access to information, it is particularly vulnerable to those who take advantage of the public good that the library represents. To reduce loss and damage the library should exercise appropriate control over use and borrowing.

\section{(4) Building Resources}

The library should be housed in one or more buildings adequate to its role within the university, and should reflect a coherent planning effort. That plan should be developed with the participation of all affected parties, and should be reviewed regularly to ensure that changes in expectations, academic programs, or the library and information world are taken into account.

(a) Amount of Space. The library should provide space to house collections, space for study and research, and space for associated processing and public service functions. The relationships between buildings, spaces, and functions should reflect an appropriately developed written program.

(b) Distribution of Space. The choice for the physical organization of the university library must be made in terms of its administrative organization, tempered by recognition of the costs involved. Historically, there have been several solutions to the provision of library space, some philosophically based, others based on cost and institutional style. These range from centralization in one library building to dispersal among several faculty, college or departmental libraries. Whatever the spatial mode chosen, the choice must be made in accordance with programmatic need and follow a careful process of decision. It is essential to provide the resources needed to implement the style of organization chosen.

(c) Location of Space. To fulfill their service missions, libraries need to be close to the center of campus activity. The space occupied is likely to be high in value, as is the cost of the building itself. In plan- ning library facilities, consideration should therefore be given to the possibility of using remote or compact storage for lesser-used materials. If shared storage facilities are available and economical, their use should be considered. In any such case, a solution of this kind should not make access for the user onerous. In a similar manner, space planning should take into account advances in electronic storage, transmission, and retrieval of information.

(d) Planning Needs. Because the library grows with the addition of resources (not simply books, but people, workspace, machines, and other equipment) long-term planning is essential. External changes, such as the effect of telecommunications, must also be taken into account. The lead time for the accumulation of capital, the preparation of working drawings, and construction require that library projects be built into long-term university space planning.

\section{(5) Programs and Services}

The resources treated in the four sections preceding are used to support programs that serve to further the university's goals. While these programs are presented here in library terms, it must be remembered that their effectiveness is measured by their utility to the user.

(a) Access. The library should develop and maintain policies and procedures for ensuring optimal access to its own collections and to needed resources available elsewhere. These policies and procedures include bibliographic control following accepted national and international standards.

i. Catalog and other records should inform the user about what is owned, where it is, and how to find it. They should be comprehensive and up-todate.

ii. Access no longer means only enabling users to find wanted materials in their library location. With the development of online catalogs, telefacsimile transmission, and other forms of information transfer, many users are now able to conduct their bibliographic research outside the library. In such instances, providing access implies the delivery of information, whether in printed or electronic format, by the library to the user at the user's location. This process should be reflected in the policies and procedures of the university library.

iii. Collections should be systematically arranged, using a readily understandable taxonomy. The library should not unduly restrict access, but should take account of the need to preserve fragile materials. If storage facilities are used, retrieval should not place an undue burden on the user.

iv. The library should arrange to check collection availability at regular intervals.

$\mathrm{v}$. The goal is to make library resources accessible to all members of the institutional community, in accordance with their needs and with regard for the preservation of materials, compliance with legal requirements such as copyright, and the right to 
personal privacy.

vi. The rules and regulations for the use of the library and its collections should be readily accessible to users.

(b) Explanation of Resources and Services. The library should provide directional, informational, and reference services. These services include not only the answering of questions and providing instruction in the use of the library, but also the provision of printed, graphic, or electronic aids.

i. The library should provide services designed for all levels of user. By teaching, by using printed guides and bibliographies, by developing electronic aids, and by personal interactions, the library staff should seek to assist users in finding needed material and developing appropriate search strategies.

ii. Bibliographic instruction, both formal and informal, should play a significant role in helping library users improve their skills.

iii. Library design should also play a role in making the library understandable. Similarly, new services such as online catalogs should be designed with the user in mind.

iv. These services should be provided not only in the library itself but also in the classroom and through public media, both on and off campus.

(c) Information Transfer. There are two kinds of information transfer: the physical transfer of documents and facsimiles of documents, and the transfer of data electronically.

i. The library should participate in local, regional, and national programs for interlibrary loan, telefacsimile, and document delivery. The rules and conditions relating to these programs should be clearly explained. Where charges are required, this should be made clear to potential users; similarly, where restrictions apply.

ii. The library should be prepared, wherever appropriate, to facilitate direct transfer to the user of information so available, as, for example, from databanks, or by referral to other agencies capable of meeting the need.

\section{(6) University-wide Programs}

To fulfill its goals, the library requires certain levels of support from within the institution. This in turn requires clear relationships with other parts of the university.

(a) General Requirements. The library should cooperate with and participate in all university services and programs concerned with information and communication. These activities include such functions as admissions, development, public relations, computer services, telecommunications, audiovisual services, publishing, copyright, royalty, depository, and exchange arrangements.

(b) Computer and Telecommunications Services. The close link between the library's information services and the provision of computer and telecommunications services for the university as a whole requires that a relationship be established, and that the development of all such services be seen as a unified university responsibility.

(c) Other Services. Other internal relationships are less direct, but equally important to the mission of the library. The library is, for example, a factor in attracting students and faculty. Because the library plays a central role in research and teaching, it should be involved in plans for the development of the university. Where access to library services is made possible for any external community, for example, the surrounding community or the residents of a state, such policy decisions should be made with full library consultation.

\section{(7) Cooperative Programs}

The library exists within a network of relationships extending beyond the institution. These relationships may be customary, contractual, cooperative, or symbolic.

In cooperation with other libraries, consortia, networks, vendors and other agencies, the library should participate in programs that will assist it in meeting its goals and are consistent with the mission of the university.

\section{(8) Responsiveness to Change}

The library should anticipate changes in the field of information. While this need not mean that the library itself should undertake a particular service, the library should bring that service and its implications to the attention of the university community.

(a) New Technology. The library should adopt and maintain new technologies as they develop and are useful in meeting its goals. New services do not totally replace older ones, and the institution must be prepared to provide needed support for an increasing range of information technologies.

(b) Experimentation. The library should be conceived as existing within and central to a network of information services, rather than as a stand alone function. The library needs to assess, by testing and experimentation, the role of new information formats as they emerge.

\section{Section C: Measuring Achievement}

The responsibility for the evaluation of the library lies with the university administration.

The university and the library administration together should establish a mechanism to measure the level of achievement of the library.

This mechanism should establish identifiable outcomes, both qualitative and quantitative, using agreed-on criteria, and providing appropriate feedback. The process should be continuous rather than unitary, though it must also fit into any process established by the university for selfevaluation.

The goal is to arrive at a clearly stated set of expectations, which can be matched against the re- 
sources needed, in both cases with the support and understanding of the library and the other participants in the process.

There is no single best way of measuring achievement. A variety of procedures should be used. The budgetary process is one of these, in the course of which goals are set and their achievement measured. Annual reports review progress and set new goals. Accreditation visits offer similar opportunities. Ongoing interactive communication with committees and other advisory groups is a necessary complement. All these activities provide a setting, based on economic and political realities, within which the review process can go forward.

Inevitably, comparisons will be made with libraries in other universities. Although such comparisons are difficult because of major differences among both institutions and libraries, comparative judgments can be made. These should be aided by appropriate quantitative measures and should not be based solely on subjective evaluations. The critical point is that, if the institution determines to use peer evaluation, the library and the university should agree on a list of institutions having similar missions, goals and programs. This enables the evaluator to avoid comparing dissimilar libraries.

All these procedures recognize that the library is not static but dynamic and needs to be evaluated from that perspective. As the goals and needs of the university change so do those of the library. Past measures may no longer be important and new ones may need to be found. An example that has emerged over recent years is the use of access rather than ownership of materials as a criterion.

Any evaluation requires that the responsibility for the evaluation be clearly assigned, the procedure to be followed be understood by all participants, and the goal be defined.

\section{(1) Participants}

The participants will vary, depending on whether the review is annual, in which case they are likely to be internal to the institution. If the review is periodic, the review team is likely to be external. Such external review may also be linked to accreditation or other mandated reviews of the whole institution. Whatever the basis for the review, the members of the review team should be agreed on by the library and university administrations. The reviewers should be informed of the procedures to be followed, and provided with appropriate documentation. Reports and testimony from both library and non-library sources are proper, in particular from those intimately concerned with the setting of goals.

The report resulting from the review should be made available to both library and university administrators, but acceptance, rejection and any subsequent implementation of recommendations are the responsibility of the university administrator who is responsible for the library.

\section{(2) Process}

The procedure followed should parallel that for any major academic or administrative unit.

(a) Annual Review. This kind of review is usually associated with the development of the library budget, and will, therefore, consist principally of a dialogue among those responsible for that process. There should be provision for review and discussion of the library's budget presentation, together with review of goals and objectives. The dialogue should give all parties the opportunity to examine the relationships between resources and expectations without preconditions.

Similarly, the annual reporting process provides an opportunity for review of successes and failures, and for the development of new goals. These processes can be formal or informal as required by the university.

(b) Periodic Review. Reviews of this nature, whether carried out by internal or external review teams should include self-assessment, examination by the review team, and review of any reports and recommendations by the university and the library.

The process of self assessment should provide adequate time for the preparation of the necessary information, and for preliminary review within the university. If the review team requires further information, time should be allowed for its preparation. This process should involve all parties concerned with the university library.

The review should allow for consultation with the appropriate persons concerned with the library and should not be subject to prior decisions as to results.

The resulting reports and recommendations should be reviewed by the appropriate library and university administrators, and there should be an opportunity to clarify misunderstandings and supply further evidence.

Criteria for the evaluation of library resources and services are set out in the following section of these standards. All criteria need to be adapted to the circumstances of each institution, as part of the process of review. All criteria should reflect the views of all participants and be stated clearly.

\section{(3) Product}

The results of any review or evaluation should be made available in written form to those responsible for administering the library, who should be given the chance to respond or to amplify. The final review should then become the basis for future action by the institution.

The outcome of reporting and discussion should be a reassessment of the library's goals and objectives. It should take into account budgetary and operational limitations, and should establish realistic expectations for the future. By this process the university and the library can maintain a practical balance between resources and mission. 


\section{Section D: Evaluative Criteria}

The questions that follow are suggested as a means of reaching a proper assessment of the library. There may be others that are more appropriate for any individual university library and all libraries should use any measures that are available locally.

\section{(1) Adequacy of Budget}

(a) Are the budgetary resources sufficient to support current activities and to provide for future development?

(b) Does the budget support the purchase of or access to the necessary range of library materials?

(c) Does the budget support appropriate numbers and kinds of staff for the programs offered?

(d) Does the budget provide adequate support for other operating expenses?

(e) Does the budget provide adequate support for new programs and innovations?

(f) Does the process by which the budget is developed allow for appropriate consultation?

(g) Does the library director have the appropriate level of discretion and control over the expenditure of the allocated budget?

\section{(2) Adequacy of Collection}

(a) Is there a written policy for managing the collection?

(b) Does this policy address issues of user satisfaction?

(c) Is there provision for considering change in academic needs?

(d) What basis is used for determining collection levels and sizes?

(e) Is there evidence of areas of undersupply?

(f) Is there evidence of areas of oversupply?

(g) Does the collection match the academic programs?

(h) Is the collection growing at an appropriate rate?

\section{(3) Adequacy of Buildings and Equipment}

(a) Are the buildings sufficient to house staff and collections?

(b) Are the buildings adequately maintained?

(c) Are there appropriate space plans?

(d) Is there appropriate provision for use by the handicapped?

(e) Is the range, quantity, and location of equipment adequate to the programs offered?

(f) Is the equipment adequately maintained?

(g) Is there budgetary provision for upgrading, repair or replacement?

(h) Is there evidence of planning for the use of new and improved technologies?

\section{(4) Access and Availability}

(a) Are the policies governing access and use clearly stated and readily available? (b) Are the bibliographic records appropriate?

(c) Are the collections properly housed?

(d) Are the collections actually accessible and available?

(e) How readily can the library provide materials not owned?

(f) Is the staff provided for technical services and other collection-related services sufficient for the task?

\section{(5) Preservation and Conservation}

(a) Does the library have proper environmental controls?

(b) Does the library have an emergency plan?

(c) Does the library budget have adequate provision for the preservation and repair of damaged, aged and brittle books?

(d) Does the library have adequate safeguards against loss, mutilation, and theft?

\section{(6) Resource Usage}

(a) What are the library policies for resource use?

(b) How much is the collection used?

(c) How well is the collection used?

(d) What is the fulfillment ratio?

(e) What is the relationship between collection size, collection growth rate, and collection use?

\section{(7) Adequacy of Services}

(a) What range of services is offered, over what ranges of times?

(b) Are the locations where services are offered adequate to the purpose?

(c) What statistics and other measures of quality and quantity are maintained?

(d) Is the size and distribution of public service staff adequate for the numbers and kinds of users?

\section{BI clearinghouses showcased}

The ACRL Bibliographic Instruction Section's Clearinghouse Committee will present a discussion forum at ALA Annual Conference in New Orleans entitled, "The BI Clearinghouse: Starting and Sustaining," on Saturday, July 9, from 9:30 a.m. to $12: 30$ p.m. If you are involved in a clearinghouse in your state or are interested in starting one, you are invited to join in the discussion. Representatives of four clearinghouses will discuss their experiences and answer questions. The panel will consist of Betsey Brenneman (New England Clearinghouse), Emily Okada (Indiana Clearinghouse), Mary Ann Miller (New Jersey Clearinghouse), and Joan Kaplowitz (Southern California Clearinghouse). 
"A KNOCKOUT! EBSCO will replace the Ulrich's family of serials references as the prime source of information on regular \& irregular titles."

Reference \& Research Book News, Winter 1987

"Very useful; we won't go back to Ulrich's after enjoying the luxury of having everything in one set of volumes."

Tracy Kimball, St. John's College Library

"This authoritative resource is the first place to look for serials research!"

Charlene Strickland, Albuquerque Public Library

"In the comparison that counts the most, during the time the $\mathrm{EBSCO}$ directory was under review, it was able to answer several reference questions Ulrich's failed on."

Wilson Library Bulletin, February 1987

"Each time I have used THE SERIALS DIRECTORY, I have actully found the title I have been searching for. And, once the cite was found, the information given was concise and thorough."

Patty Andres, Cranbrook Academy of Art Library

"I am very pleased and cannot find one thing negative to say about it!...All in all, in my opinion this directory is in a class by itself."

Malcom S. Ware, Gulf Coast

Research Laboratory Library
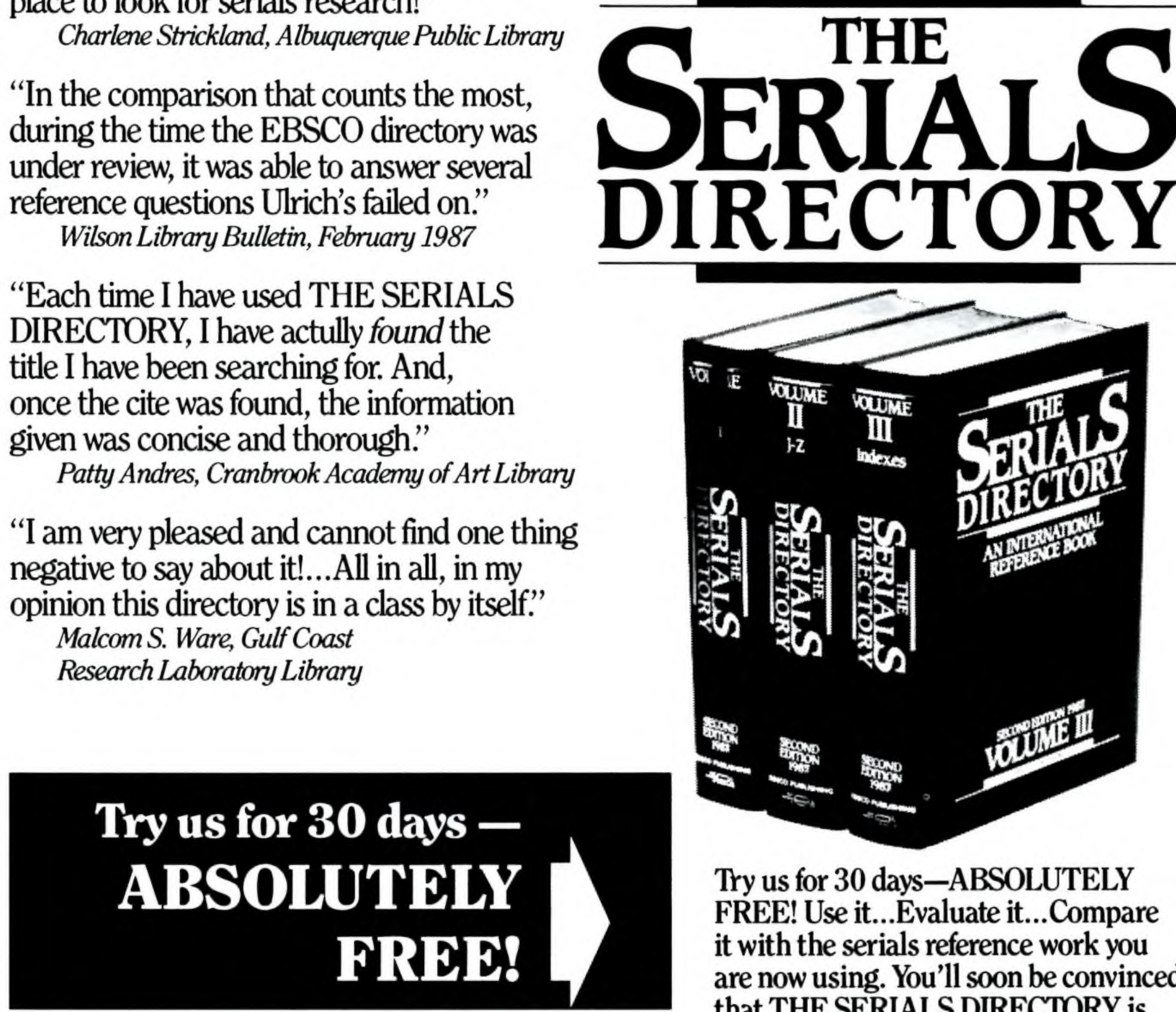

Try us for 30 days-ABSOLUTELY FREE! Use it...Evaluate it...Compare it with the serials reference work you are now using. You'll soon be convinced that THE SERIALS DIRECTORY is the most complete and up-to-date serials resource available today!

SEND YOUR ORDER TO: OR CALL TOLL-FREE:

EBSCO Publishing

P.O. Box 1943

Birmingham, AL 35201

1-800-826-3024

to reserve your copy or request more information. 